\title{
EXPERIÊNCIAS DE MICROURBANISMO: novos olhares sobre a gestão do solo urbano.
}

\author{
Tiago de Mattos Chafik Hindi \\ Tomás Antonio Moreira \\ Universidade de São Paulo \\ tiago.hindi@gmail.com \\ tomas_moreira@sc.usp.br
}

\begin{abstract}
RESUMO
A crise generalizada de representatividade política é um fenômeno ligado a uma transformação estrutural na sociedade contemporânea. O "microurbanismo" como política pública participativa vai além da consulta a população sobre suas realidades sociais e urbanas, e confere ao indivíduo o poder criativo de projeto. Por meio de seu potencial transformador, uma sociedade marginalizada e excluída pode se converter em uma democracia plena (participativa e inclusiva). O objetivo geral deste trabalho é discutir políticas públicas em habitação relacionadas a gestão do solo urbano participativa, comparando estudos de caso em Québec/CA e São Paulo/BR. Vislumbra-se uma relação entre os programas de fomento de cooperativas de habitação, a renda e a densidade demográfica em Montreal, enquanto que, na situação brasileira de urbanização recente, intensa e desorganizada, é possível indentificar características semelhantes. As políticas públicas de ambos os casos estão inscritas em dinâmicas urbanas ditadas pela forte especulação, que impele coletividades à exclusão socioespacial.
\end{abstract}

Palavras chave: Participação, microurbanismo, cooperativas habitacionais, políticas públicas.

\begin{abstract}
The widespread crisis of political representativeness is a phenomenon linked to a structural transformation in contemporary society. "Microurbanism" as a participatory public policy goes beyond consulting the population about its social and urban issues, and promotes the individual the creative power to design. Through its transforming potential, a marginalized and excluded colective may become a full democracy (participatory and inclusive). The general objective of this work is to discuss public housing policies related to participatory urban land management, comparing case studies in Québec / CA and São Paulo / BR. The relationship between housing development programs, income and population density in Montreal is noticeable, while in the Brazilian situation of recent intense and disorganized urbanization, similar characteristics are also apparent. The public policies of both cases are inscribed in urban dynamics dictated by strong speculation, which impels collectivities to social and spatial exclusion.
\end{abstract}

Keywords: Participation, Microurbanism, housing cooperatives, urban policies. 


\section{Contextualização}

Num contexto de profundas crises políticas mundiais, a democracia participativa se mostra como alternativa de desenvolvimento social e urbano, numa forma de reestruturar localidades e empoderar coletividades (Arnstein, 1969), contrapondo-se, dessa forma, a um modelo de produção de cidade excludente e alienante.

Este trabalho tem como tema central os processos de participação com foco nas políticas públicas em habitação que promovam um entendimento coletivo da produção da cidade e coloquem uma nova perspectiva sobre a democracia. Sua importância reside na identificação de potencialidades e reverberações da ação coletiva no campo do planejamento urbano em um contexto de crescente afastamento de iniciativas populares na gestão do solo urbano.

Tem como objetivo geral o estudo do microurbanismo e microprojetos urbanos, sendo eles elaborados pela população servida, em duas realidades contemporâneas distintas: na província de Québec, no Canadá (especialmente na cidade de Montreal) e no estado de São Paulo, no Brasil, relacionando-os ao envolvimento social, à qualificação do projeto e ao seu raio de abrangência. Para tanto, foram coletados dados estatísticos que constituíram base para uma cartografia destas experiências, das quais se identificam potenciais situações de aprofundamento, seja pela configuração urbana nas quais estão imersas ou pelos processos políticos que as constituíram.

Tendo em vista o contexto global de intensa transformação urbana, principalmente a partir do início do século XX e potencializado no XXI, e de um cenário de crises generalizadas, sejam econômicas, políticas e sociais, é perceptível o desgaste democrático, como presenciado em cidades europeias, norte-americanas e até mesmo latino-americanas (Moreira, 2011). A crise de representatividade política, extremismos religiosos e movimentos sociais que se espalharam por diversos países são fenômenos emergentes que estão elucidando uma transformação estrutural na sociedade (Harvey, 2013; Bauman, 2009).

Para Slavoj Žižek (2012) vive-se um momento de desconexão social e emergência de radicalismos, no qual a formação de laços sociais depende de projetos que sejam comuns a diferentes grupos. Sua proposta consistiu-se em abandonar o discurso da tolerância e construir causas comuns para que a população se engaje. Mais do que discutir a tolerância, deve-se analisar quais os pontos de convergência pelo qual ideologias comuns possam aparecer.

Ao pensar-se em projetos comuns, capazes de articular diferentes grupos, pode-se colocar a cidade como protagonista. Não que as intervenções urbanas sejam unilaterais ou consigam atender a todos os interesses, tampouco se espera amenizar totalmente os conflitos sociais presentes na cidade. A existência de conflitos é a base das estruturas urbanas. O grande desafio é construir causas comuns com as partes conflituosas (Remy e Voyé, 1992). O que se percebe é que, embora em medidas desiguais, o espaço urbano assume um papel constante na mediação de conflitos para garantir a convivência (Blanc, 1998).

Existem iniciativas que problematizam, no âmbito do planejamento urbano, a própria noção de democracia e discutem se os processos políticos e sociais que testemunhamos hoje são de fato democráticos, no sentido em que são muito mais representativos do que participativos, deixando margem de discussão quanto a legitimidade dessas decisões, conforme aponta Zetlaoui-Léger:

$\mathrm{Na}$ verdade, se trata hoje, para o Estado e coletividades locais, não apenas 'reinteressar' os cidadãos no exercício da democracia, mas através dele, trazer a legitimidade das decisões tomadas. (Zetlaoui-Léger, 2005, p. 3) [Tradução dos autores] $]^{1}$

Muitas iniciativas pautam o planejamento urbano sustentável, duradouro e participativo (Moreira e Cymbalista, 2006). Dentre elas, inúmeras formas de rever os processos de construção de cidades estão sendo rediscutidos na intenção de retomar o indivíduo como objeto central do projeto arquitetônico e urbano.

É nesse sentido que iniciativas na França, por exemplo, estão se produzindo (Metrá, 2012). Em vista de um número crescente nas abstenções de voto nas últimas eleições, dirigentes e parcelas do poder privado se depararam com fortes crises de representação e atuação política. Contra essas tendências existem exemplos,

1 “En fait, il s'agit aujourd'hui pour l'État et les collectivités locales, non seulement de 'réintéresser' le citoyen à l'exercice de la Démocratie, mais par là même, de mieux asseoir la légitimité des décisions prises". 
manifestadamente positivos, no México, aonde a população gerou o próprio projeto de intervenção urbana do qual faria parte (Metrá, 2012).

Processos formativos politicamente e profissionalmente permitiram que a população, por meio de um apoio técnico e jurídico, produzisse objetos urbanos. Exemplos brasileiros também podem ser considerados como de referência, como os orçamentos participativos e mais recentemente os exemplos do programa Minha Casa Minha Vida sob a modalidade Entidades (MCMV-E). Destacam-se, também, as experiências canadenses na produção de micro-urbanismo por meio das estruturas urbanas participativas.

Os exemplos canadenses nos trazem as dimensões do que pode ser o resultado destas medidas cooperativas, as quais podem exercer forte influência nas qualidades urbanas adjacentes e nos processos de apropriação urbana que a sociedade exerce. Apropriação que está diretamente relacionada com o processo criativo e produtivo destes projetos, que implicam na intervenção direta de usuários e coletividades locais.

Incentiva-se, portanto, o exercício crítico e criativo da própria localidade a construir a si própria, que, como evidenciado, pode mesmo vir a inspirar outras urbanidades que deem continuidade a processos semelhantes, inclusive trazendo luz a novas formas de solucionar problemas de escala maior.

Nesse sentido, a relação do micro-urbanismo com a política vai muito além do reconhecimento e consulta a uma população sobre as realidades sociais e urbanas, se constitui como um processo urbano de formação cidadã e política (Parazelli e Latendresse, 2006). Essa concepção de urbanismo confere ao usuário o poder criativo de projeto, como se mostra um processo estruturante de uma urbanidade existente, com capacidade formativa de uma sociedade marginalizada e excluída a uma democracia plena (participativa ao invés de representativa). Como afirma Zetlaoui-Léger, embora tenha se produzido uma grande quantidade de normativas capazes de tornar processos de urbanização mais racionais, muitas vezes estes são incompatíveis com o cotidiano e práticas de moradores, levando espaços públicos ao abandono:

[...] uma vez que, nestes últimos quarenta anos, nunca parou de se produzir normas ou recomendações específicas, e tentar tornar mais racionais processos de programação e projeto, percebe-se muitas vezes uma incompatibilidade dos espaços construídos em relação as práticas cotidianas dos moradores ou usuários, que podem levar ao fracasso de apropriação ou à degradação acelerada de certos lugares. (Zetlaoui-Léger, 2005, p. 6) [Tradução dos autores]²

O microurbanismo, contudo, devido a sua natureza participativa, resulta num processo de apropriação urbana positivo, em vista de identidades urbanas e coletivas mais fortes (Metrá, 2012; Pescador, 2011). Sua implantação pode ser mais demorada, mas se mostra mais duradoura em longo prazo. Ela pode, além de complementar urbanisticamente uma localidade, contribuir para a formação técnica de cidadãos, através de sistemas de cooperativismo, o que permite um desenvolvimento social concomitante com o desenvolvimento urbano.

O processo de longo prazo, contudo, não é prejudicado por sua morosidade, dado o seu caráter transformador e consolidante. Questões pedagógicas de reformas urbanas e sociais são implantadas associadas a projetos arquitetônicos e urbanos, de forma que a coletivização e democratização do espaço são materializados na cidade.

Dessa forma, essas ainda incipientes práticas urbanas se aproximam da nova agenda urbana proposta pela conferência Habitat 3 , pelo seu caráter de protagonização do usuário em sua forma coletivizante, antagonizando-se, portanto, a lógica mercantil do capital imobiliário (ONU-Habitat, 2016).

Questões antes abordadas, como processos de mutirão, autogestão e cooperativismo, protagonizadas ativamente por agentes coletivos, hoje perderam suas forças graças a mão gentrificante e excludente do capital, marginalizando comunidades, e impedindo o acesso à cidade a várias pessoas. Estas discussões, levantadas como respostas às recentes experiências de gentrificação nos centros urbanos, têm elencado inúmeras possiblidades de revisão dos processos políticos de definição de políticas urbanas e habitacionais.

“[...] alors qu'on n'a eu de cesse ces quarante dernières années de produire un grand nombre de normes ou de recommandations précises, et d'essayer de rendre plus rationnels les processus de programmation et de conception, on constate souvent une inadéquation des espaces bâtis aux pratiques de vie quotidienne des habitants ou usagers, pouvant conduire a un défaut d'appropriation et a une dégradation accélérée de certains lieux." 
Novamente se coloca o sujeito usuário das cidades como ponto de partida, embora ainda com muita dificuldade do poder público. Os atuais debates em torno destas novas noções de democracia e política são fundamentais para a prática e sucesso da nova agenda urbana.

\section{Metodologia}

Para o desenvolvimento deste processo investigativo foi empregado o método de Estudo de Caso Comparativo, utilizando-se levantamento bibliográfico e documental referentes as políticas públicas de habitação popular dos países selecionados (especificamente as políticas públicas sobre cooperativas de habitação no Quebec/CA e o Minha Casa Minha Vida no estado de São Paulo/BR).

Decorreu-se a análise dos bancos de dados disponibilizados pelos agentes atuantes no desenvolvimento do programa: Caixa Econômica Federal (CEF); movimentos sociais ou órgãos públicos; pelo governo do Quebec; e da Federação de Cooperativas de Habitação Intermunicipal de Montreal Metropolitano (FECHIMM). Quanto a fase empírica, foram feitas visitas a campo, que possibilitaram levantamentos de dados e fotografias.

A partir do estudo teórico inicial, as abordagens empíricas (feitas através de visitas a campo e entrevistas) permitiram a caracterização e acompanhamento da realidade atual e a possibilidade da formulação de um juízo crítico em relação a ela.

Foram realizadas também entrevistas semiestruturadas com agentes ativos nesses processos. Buscou-se, para a seleção destas pessoas, a relação e afinidade com o tema, assim como a sua atuação presente e passada. Elaborou-se um modelo de perguntas para que se seguisse, mas foi permitido a resposta em bloco ou separadamente, assim como comentários e adendos necessários ao desenvolvimento da resposta, levando a um discurso completo por parte do(a) entrevistado(a).

Em função do tema abordado na presente pesquisa foram selecionadas três pessoas para as entrevistas, em vista do histórico de atuação em movimentos participativos. A primeira entrevistada, Bibiana Barreto Silveira, advogada e representante jurídica do movimento social urbano "Em busca de um sonho", que luta por moradia digna na cidade de São Carlos. A segunda pessoa, Eleusina Lavôr Holanda de Freitas, arquiteta e pesquisadora, e sempre presente no cenário político, atuando ativamente em processos participativos. $O$ terceiro, Francisco de Assis Comaru, engenheiro civil e professor, atuou ativamente em questões políticas que envolvem participação e movimentos sociais.

Ao final, emprega-se uma análise comparativa dos dados afim de relacionar o estudo teórico, realizado inicialmente no período de pesquisa, os dados coletados empiricamente pelas visitas e conversas informais e as entrevistas, compondo uma conclusão baseada nas diversas contribuições dos meios de coleta de informações.

\section{Casos de análise}

Em função deste contexto de crise política, identificam-se dois casos específicos de declínio de processos participativos antes pujantes: na província de Québec no Canadá, e no estado de São Paulo, no Brasil. Ambas localidades possuem um histórico de fomento de atividades participativas em questões habitacionais, mas que se mostram atualmente em decadência, conforme nos mostram os dados e mapeamentos levantados durante o período de pesquisa.

Para que se entenda esta configuração atual, deve ser entendido como esses processos se constituíram através do tempo, e entender esses processos como integrantes de um cenário político abrangente, que é constituído por inúmeras variáveis. A escolha destes cenários busca comparar realidades distintas, de forma a produzir informações que levem ao entendimento quanto a materialização e espacialização resultante da interação destas variáveis políticas.

\subsection{Québec/CA}

A realidade canadense é ilustrativa deste cenário global de crises. De toda a província de Québec se sobressai, na cidade de Montreal, uma ampla manifestação desta forma cooperativa de habitar a cidade. 
Embora ainda em grande quantidade, percebe-se empiricamente o declínio dos conjuntos habitacionais em modelo cooperativo. Foi, portanto, utilizada esta cidade como estudo de caso a ser comparado e aprofundado.

Como dito anteriormente, as atuais tendências urbanas da cidade não fogem a este cenário de crise e se comportam de maneira análoga aos processos que existem no Brasil. Embora tenha existido um grande fomento federal, provincial e municipal na cidade de Montreal desde o fim da década de 60 (Decroly, 2003), questões associadas ao mercado imobiliário atualmente reformulam políticas públicas de apoio a constituição e organização de novas cooperativas de habitação, bem como a manutenção das já existentes.

Segundo Bouchard e Hudon (2005), o governo canadense sempre apoiou, de forma geral, o acesso à propriedade e à moradia a todas as classes populares, em geral possibilitando a construção. As primeiras iniciativas cooperadas no Québec, datando de 1968, não obtiveram êxito devido a grande necessidade burocrática inerente ao processo. O que se desdobra destas primeiras experiências, ainda segundo Bouchard e Hudon (2005), é a integração dos futuros usuários ao processo de constituição da cooperativa.

Em função destes aprendizados surgem grupos de apoio técnico às iniciativas cooperadas, possibilitando, portanto, o acesso a projetos técnicos de qualidade que possuem ampla participação dos usuários futuros e garantem o bom desenvolvimento urbano da região.

A necessidade de moradia se transforma numa nova lógica de habitação, identificada como uma vida coletiva e de miscigenação de classes ao invés de um meio de acumulação de capital. Decorrem deste período os programas de fomento as cooperativas de habitação e a sua disseminação, culminando em uma grande quantidade de unidades residenciais em sistemas cooperativados.

São reflexos desse período as grandes políticas de fomento a habitação cooperada, tanto em nível federal quanto provincial e municipal. Ao todo, somam-se cinco programas federais, três de iniciativa federalprovincial com a província de Québec, seis de iniciativa provincial e cinco de iniciativa da municipalidade de Montreal, totalizando quatorze programas para a província de Québec e dezenove para a cidade de Montreal. Somente na cidade são registrados 454 conjuntos em modelo cooperativo, representando 11.323 unidades habitacionais, divididas entre os programas de fomento.

Atualmente percebem-se tendências contrárias a esse processo histórico de inclusão social. Ainda que não seja ainda consenso entre os gestores e pesquisadores Montrealeses, é possível verificar empiricamente (Figura 01 e 02) que a região sudoeste de Montreal, especificamente a região denominada Pointe St-Charles, é alvo atual de intensa gentrificação, o que leva as cooperativas existentes a deixarem de existir, devido à elevação dos preços da região. Atualmente, habitações e comércios de alto padrão estão se espalhando por toda a região sul de Montreal, deixando apenas algumas poucas habitações populares ainda resistentes. Essa tendência contrária e excludente reflete a lógica de urbanização e políticas públicas mercantilizada, que vai contra a evolução marcada pela miscigenação de classes sociais e produção coletiva da habitação.

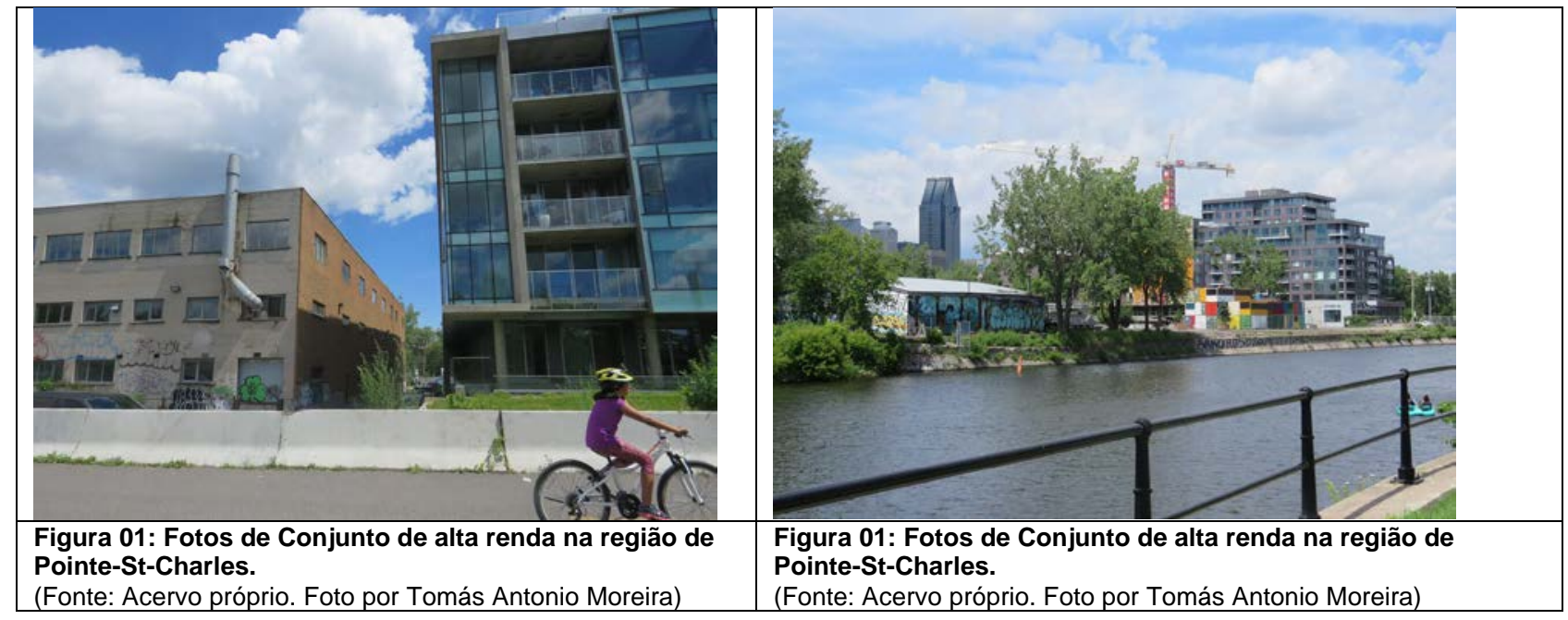

Dada esta configuração, foi elaborada uma relação das cooperativas de habitação existentes hoje na cidade de Montreal, filiadas a Federação de Cooperativas de Habitação de Montreal e região Metropolitana 
(FECHIMM). Esta síntese relaciona a localização das cooperativas com a quantidade de unidades em função de seu programa de fomento (Tabela 01).

Essa tabela explicita a relação existente entre os diversos programas de fomento às cooperativas habitacionais, apoiadas desde a década de 70 , e a sua posição geográfica na cidade. Não somente sua posição, mas também o número e o tipo de unidades são reflexo da valorização decorrente das especulações financeiras do capital imobiliário, hoje voltadas a área centro sul, especificamente nos bairros do Plateau Mont-Royal, Ville Mairie e Vieux Montréal, Pointe St-Charles e Hochelaga-Maisonneuve, identificados no mapa abaixo, que identifica a posição geográfica destes bairros (Figura 03).

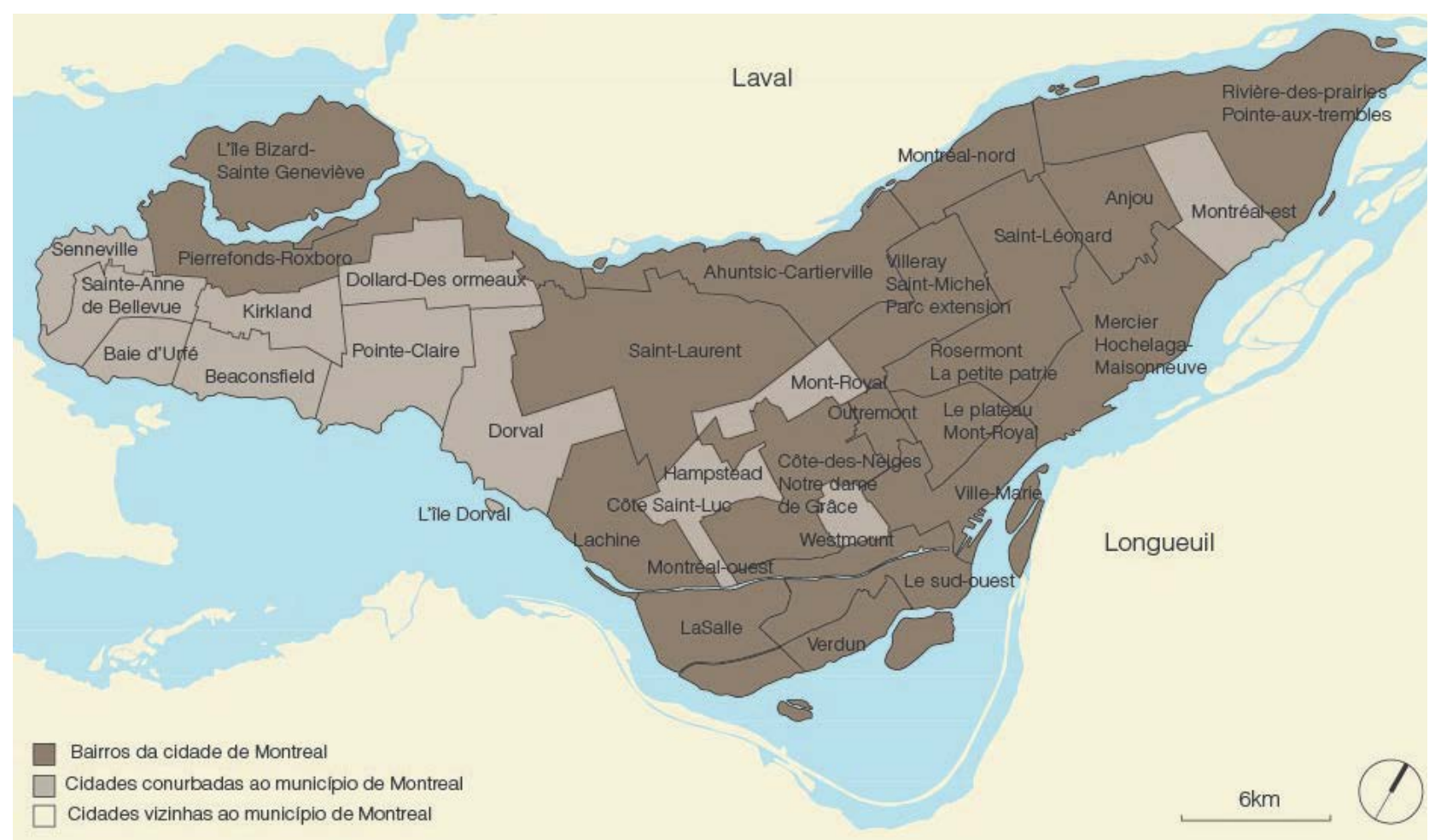

Figura 03: Mapa dos bairros da cidade de Montreal.

(acervo próprio, com base nos dados disponibilizados em:

http://ville. montreal.qc.ca/portal/page? pageid $=5798,85813661 \&$ dad=portal\& schema=PORTAL) 


\begin{tabular}{|c|c|c|c|c|c|c|c|c|c|c|c|c|c|c|c|c|c|c|c|c|}
\hline \multirow{2}{*}{ LOCALIZAÇÃO* } & \multicolumn{20}{|c|}{ PROGRAMAS } \\
\hline & - & 56 & $\mathrm{ACL}$ & AL & Art.61 & Art.95 & FIM & HP & $\angle A Q$ & MIXTE & PALL & PARCO & PHASO & PHI & PIC-96 & PIQ & PSBLP & RENO & RES-M & total \\
\hline 01 & 0 & 0 & 8 & 1 & 0 & 6 & 0 & 0 & 2 & 0 & 0 & 0 & 0 & 1 & 0 & 0 & 3 & 0 & 0 & 21 \\
\hline 02 & 0 & 0 & 12 & 0 & 1 & 8 & 0 & 0 & 1 & 1 & 2 & 3 & 0 & 2 & 0 & 0 & 0 & 0 & 0 & 30 \\
\hline 03 & 0 & 0 & 7 & 0 & 1 & 3 & 0 & 0 & 0 & 0 & 0 & 0 & 0 & 2 & 0 & 0 & 3 & 0 & 0 & 16 \\
\hline 04 & 1 & 0 & 4 & 0 & 0 & 3 & 0 & 0 & 0 & 0 & 0 & 1 & 0 & 2 & 0 & 0 & 0 & 1 & 0 & 12 \\
\hline 05 & 0 & 1 & 24 & 0 & 3 & 24 & 1 & 1 & 0 & 0 & 0 & 1 & 0 & 12 & 0 & 0 & 6 & 0 & 0 & 73 \\
\hline 06 & 0 & 0 & 1 & 0 & 0 & 1 & 0 & 0 & 0 & 0 & 0 & 0 & 0 & 7 & 0 & 0 & 0 & 0 & 0 & 9 \\
\hline 07 & 0 & 0 & 6 & 0 & 1 & 4 & 0 & 1 & 2 & 0 & 0 & 1 & 0 & 3 & 0 & 0 & 1 & 0 & 0 & 19 \\
\hline 08 & 1 & 0 & 3 & 0 & 2 & 26 & 0 & 1 & 0 & 0 & 0 & 0 & 0 & 3 & 0 & 1 & 0 & 0 & 1 & 37 \\
\hline 09 & 1 & 1 & 10 & 0 & 0 & 16 & 0 & 0 & 0 & 2 & 1 & 3 & 0 & 7 & 0 & 0 & 4 & 0 & 0 & 45 \\
\hline 10 & 0 & 1 & 10 & 0 & 2 & 24 & 0 & 0 & 1 & 1 & 1 & 1 & 3 & 4 & 1 & 0 & 17 & 0 & 0 & 66 \\
\hline 11 & 0 & 1 & 5 & 0 & 0 & 17 & 0 & 0 & 0 & 0 & 0 & 1 & 0 & 0 & 0 & 0 & 0 & 0 & 0 & 24 \\
\hline 12 & 2 & 1 & 13 & 0 & 1 & 28 & 0 & 0 & 1 & 1 & 1 & 7 & 0 & 9 & 0 & 5 & 0 & 0 & 0 & 69 \\
\hline 13 & 0 & 0 & 14 & 0 & 0 & 10 & 0 & 0 & 1 & 0 & 1 & 1 & 0 & 5 & 0 & 0 & 1 & 0 & 0 & 33 \\
\hline TOTAL & 5 & 5 & 117 & 1 & 11 & 170 & 1 & 3 & 8 & 5 & 6 & 19 & 3 & 57 & 1 & 6 & 35 & 1 & 1 & 454 \\
\hline
\end{tabular}

\begin{tabular}{|c|c|c|c|c|c|c|c|c|c|c|c|c|c|c|c|c|c|c|c|c|}
\hline \multirow{2}{*}{ LOCALIZAÇÃO } & \multicolumn{20}{|c|}{ UNIDADES / PROGRAMA } \\
\hline & - & 56 & ACL & AL & Art.61 & Art.95 & FIM & HP & LAQ & MIXTE & PALL & PARCO & PHASO & PHI & PIC-96 & PIQ & PSBLP & RENO & RES-M & total \\
\hline 01 & 0 & 0 & 239 & 56 & 0 & 162 & 0 & 0 & 130 & 0 & 0 & 0 & 0 & 39 & 0 & 0 & 98 & 0 & 0 & 724 \\
\hline 02 & 0 & 0 & 269 & 0 & 94 & 158 & 0 & 0 & 71 & 28 & 54 & 68 & 0 & 40 & 0 & 0 & 0 & 0 & 0 & 782 \\
\hline 03 & 0 & 0 & 275 & 0 & 6 & 59 & 0 & 0 & 0 & 0 & 0 & 0 & 0 & 58 & 0 & 0 & 86 & 0 & 0 & 484 \\
\hline 04 & 16 & 0 & 177 & 0 & 0 & 57 & 0 & 0 & 0 & 0 & 0 & 30 & 0 & 28 & 0 & 0 & 0 & 15 & 0 & 323 \\
\hline 05 & 0 & 14 & 977 & 0 & 33 & 461 & 8 & 20 & 0 & 0 & 0 & 25 & 0 & 319 & 0 & 0 & 98 & 0 & 0 & 1955 \\
\hline 06 & 0 & 0 & 18 & 0 & 0 & 18 & 0 & 0 & 0 & 0 & 0 & 0 & 0 & 185 & 0 & 0 & 0 & 0 & 0 & 221 \\
\hline 07 & 0 & 0 & 168 & 0 & 20 & 292 & 0 & 766 & 85 & 0 & 0 & 19 & 0 & 78 & 0 & 0 & 24 & 0 & 0 & 1452 \\
\hline 08 & 15 & 0 & 88 & 0 & 31 & 417 & 0 & 7 & 0 & 0 & 0 & 0 & 0 & 43 & 0 & 19 & 0 & 0 & 44 & 620 \\
\hline 09 & 77 & 38 & 310 & 0 & 0 & 306 & 0 & 0 & 0 & 16 & 45 & 58 & 0 & 192 & 0 & 0 & 81 & 0 & 0 & 1123 \\
\hline 10 & 0 & 6 & 270 & 0 & 24 & 399 & 0 & 0 & 18 & 16 & 48 & 12 & 42 & 79 & 6 & 0 & 289 & 0 & 0 & 1209 \\
\hline 11 & 0 & 12 & 90 & 0 & 0 & 236 & 0 & 0 & 0 & 0 & 0 & 21 & 0 & 0 & 0 & 0 & 0 & 0 & 0 & 359 \\
\hline 12 & 88 & 6 & 359 & 0 & 22 & 380 & 0 & 0 & 49 & 56 & 17 & 97 & 0 & 122 & 0 & 55 & 0 & 0 & 0 & 1251 \\
\hline 13 & 0 & 0 & 418 & 0 & 0 & 166 & 0 & 0 & 53 & 0 & 23 & 23 & 0 & 125 & 0 & 0 & 12 & 0 & 0 & 820 \\
\hline TOTAL & 196 & 76 & 3658 & 56 & 230 & 3111 & 8 & 793 & 406 & 116 & 187 & 353 & 42 & 1308 & 6 & 74 & 688 & 15 & 44 & 11323 \\
\hline
\end{tabular}

Tabela 01: Quadro síntese das cooperativas de Montreal, relacionando a quantidade de programas e de unidades aos bairros da cidade de Montreal. (tabela de acervo próprio, produzida a partir dos dados disponibilizados pela FECHIMM.)

Legenda:

01 - Ahuntsic-Cartierville e St-Laurent

-De-Grâce, Côte SaintLuc e Outremont

04 - Laval et laurentides

05 - Mercier-hochelaga-maisonneuve

06 - Montréal-nord
07 - Ouest de l'île

09 - Rosemont-pent-Royal

10 - Sud-ouest

11 - Verdun

12 - Ville-marie

13 - Villeray-saint e Michel-parc extension
- - Informação ausente

ACL-

AL - 61

Art. $61-$

F.I.M. -

H.P. - Hors programme

L.A.Q. -
MIXTE. -
PALL-

PARCO -

PHI -

PIC $96-$

PIQ -

PSBLP -

RES - M - 
Estes programas de fomento mostram uma configuração urbana que traz indícios quanto a população que ocupa as respectivas cooperativas. Isso nos permite identificar uma espacialização dos programas de cooperativas, ilustrando que alguns bairros (Figura 03) são notáveis por um cenário de gentrificação pós década de 90 (Decroly, 2003), apresentando programas cooperativos divergentes de outros, com população imigrante e de baixa renda.

Para além disso, se interpolarmos a densidade demogrática (Figura 04) e distribuição de renda no município de Montreal (Figura 05) à distribuição dos programas de cooperativas habitacionais (Figura 06), percebe-se uma possível associação entre faixas de renda e alguns programas, assim como uma discrepância em relação ao número de unidades por programa.

O programa Accès Logis ( $\mathrm{ACL}$ ) por exemplo, está localizado em uma região de maior densidade demográfica e baixa renda média, comportando 117 das 454 cooperativas cadastradas à federação, mas comporta $32 \%$ das unidades em modelo cooperativo da cidade de Montreal (3.658 unidades).

Em contrapartida, a modalidade Hors programme (HP), possui apenas três cooperativas das 454 cadastradas, mas é responsável por $7 \%$ do total de unidades em modelo cooperativo, e está localizado numa área de elevado poder aquisitivo e baixa densidade demográfica.

Dessa maneira se sobressaem cinco programas ilustrativos da realidade de Montreal: Accès Logis (ACL); Lei Nacional de Habitação (art. 95); Prêt hypothécaire indexé (PHI); modalidade Hors programmes (HP) e Logement abordable Québec (LAQ).

A disparidade entre o número de empreendimentos cadastrados e de unidades (PHI e HP), o elevado número de unidades e cooperativas (ACL e art. 95) ou a localização dentro da malha urbana, onde se manifestam processos de gentrificação e exclusão social (LAQ) reflete a dimensão das organizações socio espaciais em função das tendências imobiliárias recentes da cidade de Montreal. Regiões atualmente sofrendo processos de gentrificação, como o Sudoeste (Point St-Charles), apresentam disparidades entre programas de fomento, indicando uma tendência especulativa sobre o espaço urbano e as recentes políticas públicas em habitação.

Dessa forma, percebe-que a valorização das áreas do centro-sul, influenciadas por uma recente reconfiguração do mercado imobiliário, reforça questões de exclusão social. As reconversões dos comércios das áreas afetadas e a produção de habitações de alto custo elevam o preço de manutenção das cooperativas existentes. Estas são, portanto, forçadas a fecharem, por serem em geral, voltadas a um público de menor poder aquisitivo, como nos mostra a Figura 05, e densamente povoadas, como mostra a Figura 04. Essa configuração presente nos leva a questionar como se organizará o espaço através do tempo, e como será a metamorfose dessa cartografia nos próximos anos. 


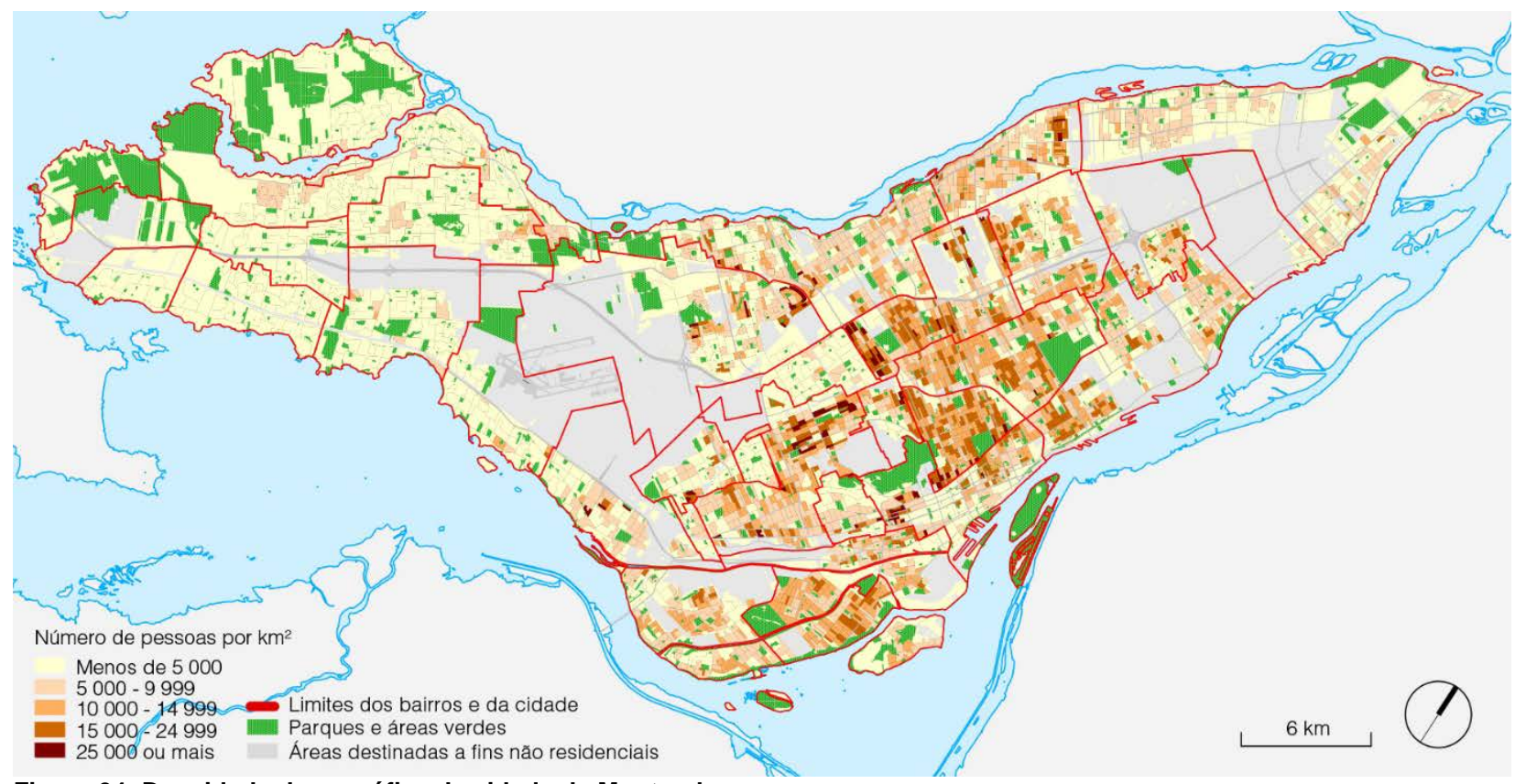

Figura 04: Densidade demográfica da cidade de Montreal.

(Fonte: http://ville.montreal.qc.ca/portal/page? pageid=6897,68087915\& dad=portal\& schema=PORTAL)

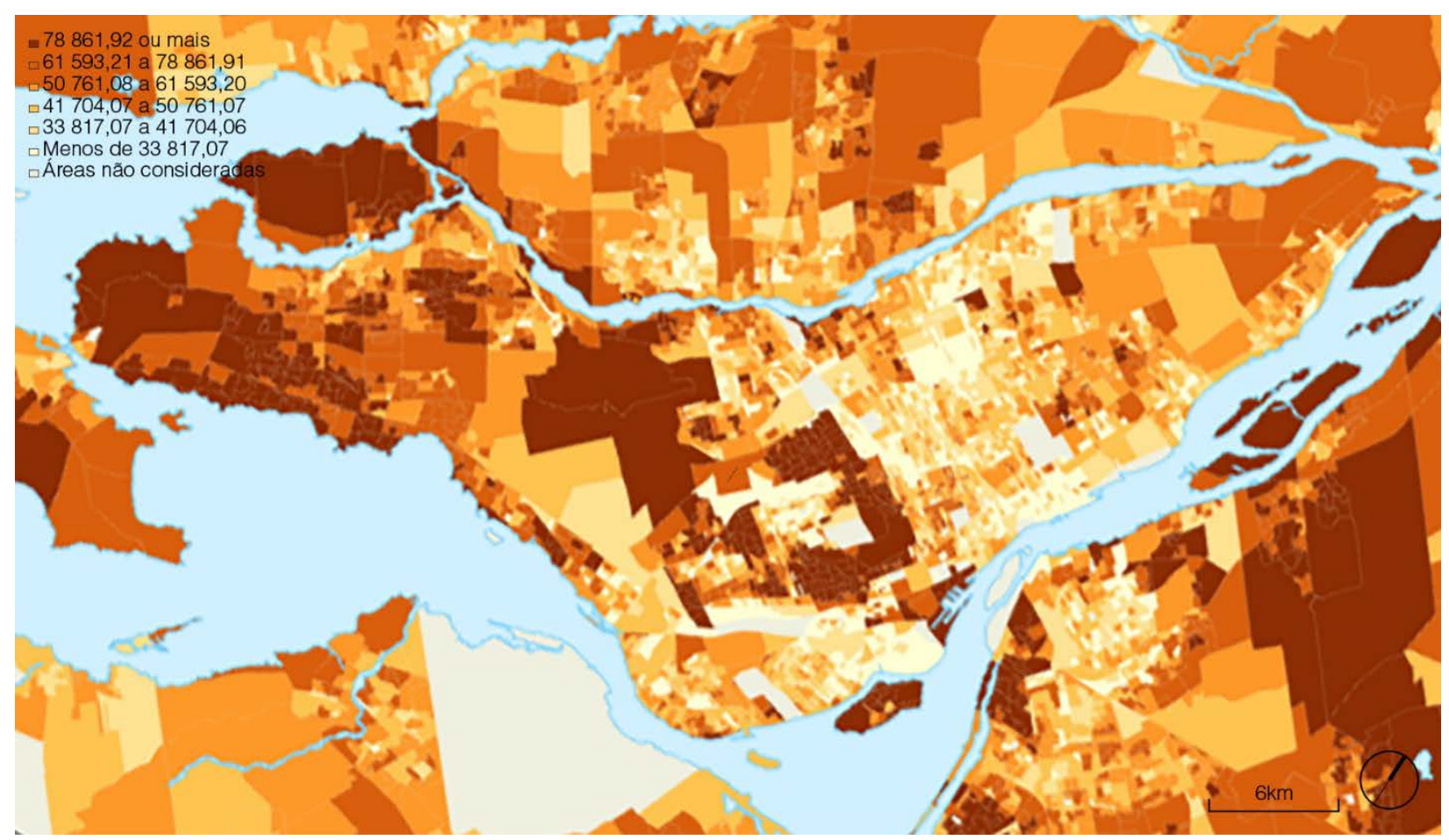

Figura 05: Distribuição de renda da cidade de Montreal (em dólares canadenses por ano).

(Fonte: http://www.msss.gouv.qc.ca/statistiques/atlas/atlas/index.php?id carte=57) 


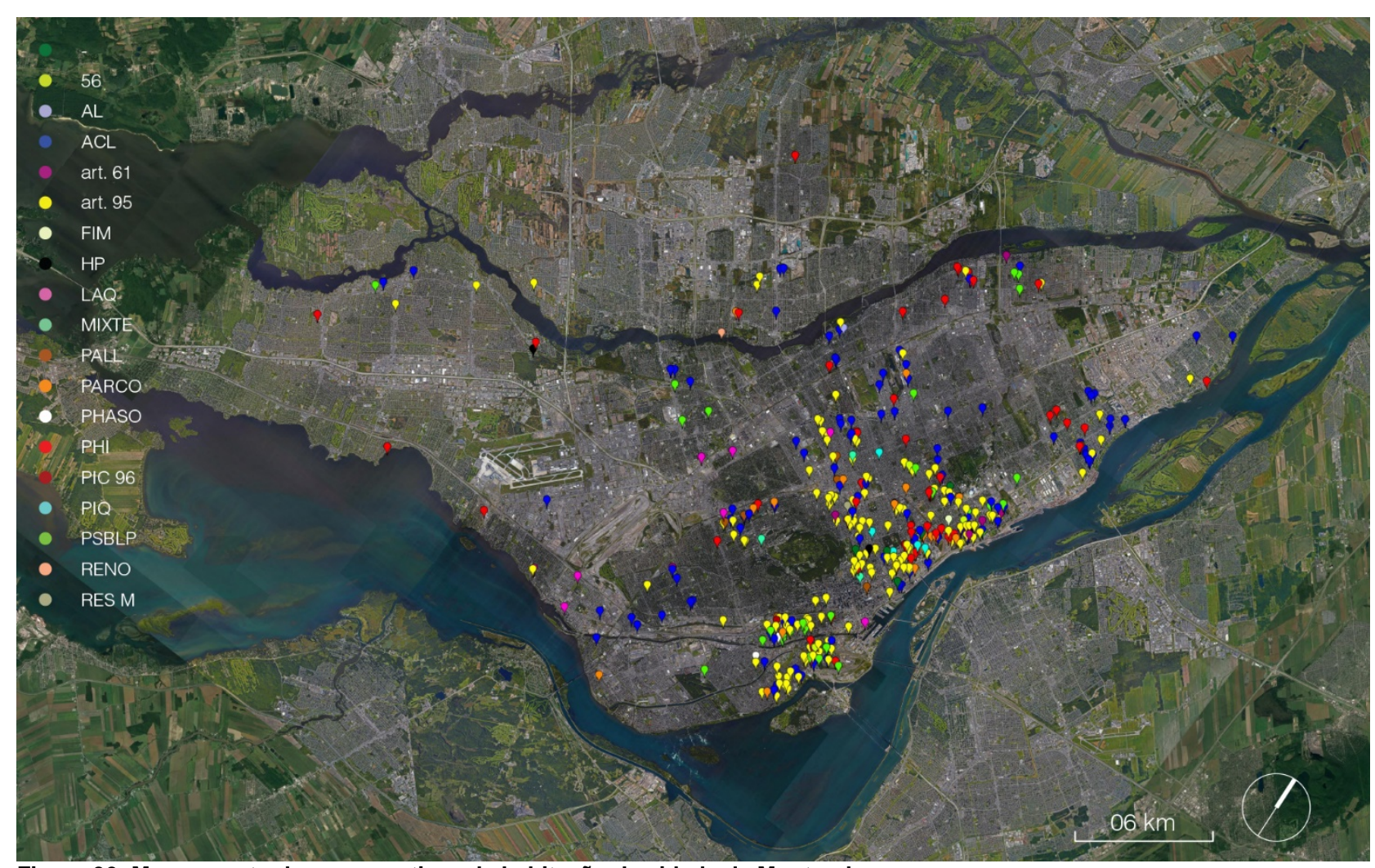

Figura 06: Mapeamento das cooperativas de habitação da cidade de Montreal.

(Fonte: Google Earth, à partir dos dados disponibilizados pela FECHIMM.)

\subsection{São Paulo/BR}

Para analisarmos o contexto brasileiro, é necessário revermos o histórico da produção de habitação social do país. Se considerarmos que o início da produção realmente relevante foi com os Institutos de Aposentadoria e Pensão (IAPs), perceberemos que o objetivo central sempre buscou a valorização territorial e imobiliária (Bonduki, 2014). Embora a produção inicial da década de 30 e 40 fosse voltada para o aluguel, com qualidade construtiva e de boa localização, a iniciativa se dá pela falta de investimentos federais para as políticas públicas, ficando a cargo dos institutos bancar tais moradias (de muito baixo volume, se considerarmos a população contemplada em relação com a demanda).

Não fosse pela falta de autonomia dos órgãos responsáveis por essa produção, a privatização da habitação social seria a realidade da época (Bonduki, 2014), o que revela que a mercantilização sempre foi consenso entre os produtores de habitação no Brasil.

O aumento de produção após o golpe militar e a posterior ditadura refletem o domínio da privatização sobre a política de habitação, sendo visível a relação entre o valor da terra e do objeto arquitetônico com a produção. Percebe-se uma valorização numérica sobre a qualidade, marginalizando uma população já socialmente vulnerável.

A partir do fim do governo FHC e início do primeiro mandato de Lula, é possível identificar um momento de retomada de direitos sociais urbanos. A aprovação do estatuto das cidades (2001), a criação do ministério das cidades (2003), do conselho das cidades (2003), do congresso das cidades (2004), do programa crédito solidário (2004) e os fundos para Habitação de Interesse Social (HIS) em (2005), juntamente com o Programa de Aceleração do Crescimento (PAC) de 2007 e o Programa Minha Casa Minha Vida (MCMV), lançado em 2009 são exemplos de como o empoderamento social urbano se desenvolveu no início do século XXI no Brasil (Ferreira, 2012).

Contudo, embora o cenário fosse favorável, as políticas de habitação colocadas em prática durante o governo Lula e Dilma revelaram ainda mais essa tendência à privatização e mercantilização da política habitacional. Abertamente desenvolvimentistas e econômicas, essas produções massivas de habitação produziram espaços muitas vezes destituídos de qualquer qualidade urbana, são nada além de um teto sob o qual se 
abrigar. Para Bonduki, esse gênero de política pública habitacional e suas produções são incoerentes com a dimensão de um país como o Brasil, onde existem inúmeras regionalidades e especificidades:

"Em um país imenso como o Brasil, implementar programas e projetos habitacionais de maneira centralizada a partir do governo federal é, ainda hoje, um problema difícil de ser equacionado, além de ser um equívoco. Com dimensões continentais e abrigando climas, culturas e modos de morar muito diferentes, parece ser bastante problemático desenvolver soluções habitacionais uniformizadas para o imenso território nacional." (Bonduki, 2014, p. 273)

Identifica-se no programa "Minha Casa Minha Vida" (MCMV) a política pública em habitação de maior abrangência do Brasil. Sua implementação, durante o governo Lula em 2009, marca uma iniciativa de contraposição à crise emergente, junto ao PAC em 2007, de incentivo à construção civil (Ferreira, 2012; Naime, 2010). Essa iniciativa, embora tenha produzido inúmeras moradias e reduzido o déficit habitacional brasileiro, produziu espaços urbanos mais segregados e isolados.

A implementação da modalidade Entidades desta política pública vem como resposta dos movimentos sociais urbanos aos produtos que o programa implementou. Evidencia-se, portanto, a necessidade dos usuários de participar dos processos de projeto e desenho dos empreendimentos (Alencar, 2010; Ferreira, 2012).

O MCMV sob a modalidade Entidades (MCMV-E) vem num sentido contrário a essa configuração mercantil em que o MCMV se insere. De acordo com Miguel Buzzar et al (2014), o programa MCMV-E foi fruto da iniciativa do movimento popular na sua luta por moradia digna, trazendo entidades sociais para o debate público da habitação. Desta maneira, entendendo este programa como a política pública habitacional de maior repercussão contemporânea no Brasil, faz-se o recorte para aprofundamento nesta modalidade do programa, que possui algum nível de participação popular, embora se saiba que enfrenta inúmeras dificuldades políticas de se implantar de maneira satisfatória, seja pela morosidade do poder público, seja pela desorganização social, ou seja pela especulação imobiliária existente em torno do tema (Rizek et al, 2014).

O levantamento de todos os empreendimentos contratados pela Caixa Econômica Federal (CEF), atual agente financeiro de políticas públicas, permitiu a síntese por estado (Tabela 02) e posterior mapeamento do caso paulista. Evidenciou-se que o estado possui uma vasta produção junto ao MCMV, com 168.186 unidades construídas, das quais 150.588 são produzidas por construtoras ou incorporadoras, e apenas as 17.598 restantes possuem algum tipo de participação popular, indicados pelas entidades contratantes do serviço junto a CEF ${ }^{3}$

Ao mapear todos os conjuntos contratados pelo programa MCMV no estado de São Paulo (Figura 05), percebe-se uma concentração de empreendimentos em núcleos urbanos conurbados, mas que, contudo, não é proporcional ao mapeamento dos empreendimentos contratados por entidades coletivas, como associações de bairro ou movimentos sociais urbanos (Figura 06). Interpreta-se disso, que o programa, por mais abrangente que seja, foi desenvolvido sem participação social.

Conclui-se, portanto, que se tratou de uma política pública ilustrativa de uma necessidade quantitativa, mais do que uma resposta às necessidades habitationais da população do estado de São Paulo. O baixo volume de produção desse tipo de empreendimento (em quantidade contratada e unidades produzidas) nos grandes centros é evidência de que a presença de agentes sociais nos processos de construção política da habitação foi evitada. Frente a isso, o MCMV-E, enquanto resposta a tendência mercantil dessa política pública habitational, pode ser interpretado como evidência dessa vontade de participação na definição de política.

\footnotetext{
${ }^{3} 1$ Dados obtidos a partir de informações coletadas junto a Caixa Econômica Federal em abril de 2017;
} 


\begin{tabular}{|c|c|c|c|c|}
\hline \multirow{2}{*}{ UF } & \multicolumn{4}{|c|}{ Quantidade por programa de contratação } \\
\hline & Imóvel rural & FAR alienação & FDS & municipios \\
\hline AC & 47 & 21 & 0 & 0 \\
\hline$A L$ & 48 & 75 & 2 & 0 \\
\hline AM & 86 & 23 & 9 & 0 \\
\hline AP & 8 & 4 & 0 & 0 \\
\hline BA & 184 & 337 & 9 & 0 \\
\hline $\mathrm{CE}$ & 55 & 94 & 5 & 0 \\
\hline DF & 7 & 2 & 0 & 0 \\
\hline ES & 110 & 30 & 0 & 0 \\
\hline GO & 204 & 88 & 61 & 0 \\
\hline MA & 347 & 192 & 12 & 0 \\
\hline MG & 625 & 308 & 24 & 1 \\
\hline MS & 45 & 60 & 23 & 0 \\
\hline $\mathrm{MT}$ & 26 & 98 & 1 & 2 \\
\hline PA & 135 & 124 & 7 & 0 \\
\hline PB & 53 & 42 & 3 & 0 \\
\hline $\mathrm{PE}$ & 113 & 110 & 12 & 0 \\
\hline PI & 143 & 64 & 6 & 0 \\
\hline PR & 775 & 170 & 5 & 1 \\
\hline RJ & 8 & 245 & 4 & 0 \\
\hline $\mathrm{RN}$ & 77 & 57 & 0 & 0 \\
\hline RO & 208 & 30 & 3 & 0 \\
\hline RR & 18 & 13 & 2 & 0 \\
\hline $\mathrm{RS}$ & 1976 & 148 & 68 & 0 \\
\hline SC & 1024 & 88 & 10 & 0 \\
\hline SE & 231 & 19 & 12 & 0 \\
\hline SP & 143 & 455 & 55 & 0 \\
\hline TO & 12 & 33 & 5 & 0 \\
\hline Total & 6708 & 2930 & 338 & 4 \\
\hline
\end{tabular}
Empreendimentos
contratados

68
125
118
12
530
154
9
140
353
551
958
128
127
266
98
235
213
951
257
134
241
33
2192
1122
262
653
50
9980

Unidades

5402

47956

26104

6667

154527

35132

6335

13749

43231

97412

116166

22237

33794

83551

15209

51320

38844

51578

85973

21184

16414

7626

65726

29542

18031

168186

12955

1274851
Investimento

$260511913,76 \$$

2342658732,74 \$

1169448665,93 \$

$361160393,27 \$$

7994443090,00 \$

1941159322,90 \$

665754286,72 \$

$605391497,74 \$$

1851016615,55 \$

$4300185790,82 \$$

5850738463,07 \$

1081203539,86 \$

$1608102094,56 \$$

4240986886,63 \$

711895955,46 \$

2396376289,23 \$

$1710303005,80 \$$

2373520993,85 \$

5482125490,90 \$

967077518,63 \$

721622406,07 \$

383022120,82 \$

2430624829,16 \$

1143335824,48 \$

681393077,84 \$

9807301068,27 \$

648820484,67 \$

63730180358,72 \$
\$ / unid

48225,09 \$

$48850,17 \$$

$44799,60 \$$

54 171,35 \$

$51734,93 \$$

$55253,31 \$$

$105091,44 \$$

$44031,67 \$$

$42816,88 \$$

44144,31 \$

$50365,33 \$$

$48621,83 \$$

$47585,43 \$$

$50759,26 \$$

$46807,55 \$$

$46694,78 \$$

$44030,04 \$$

$46018,09 \$$

$63765,66 \$$

$45651,32 \$$

$43963,84 \$$

$50225,82 \$$

$36981,18 \$$

$38702,05 \$$

$37790,09 \$$

58312,23 \$

$50082,63 \$$

49 990,30\$

Tabela 02: Relação de empreendimentos Minha Casa Minha Vida por estado.

Fonte: acervo próprio, com base nos dados disponibilizados pela CEF. 


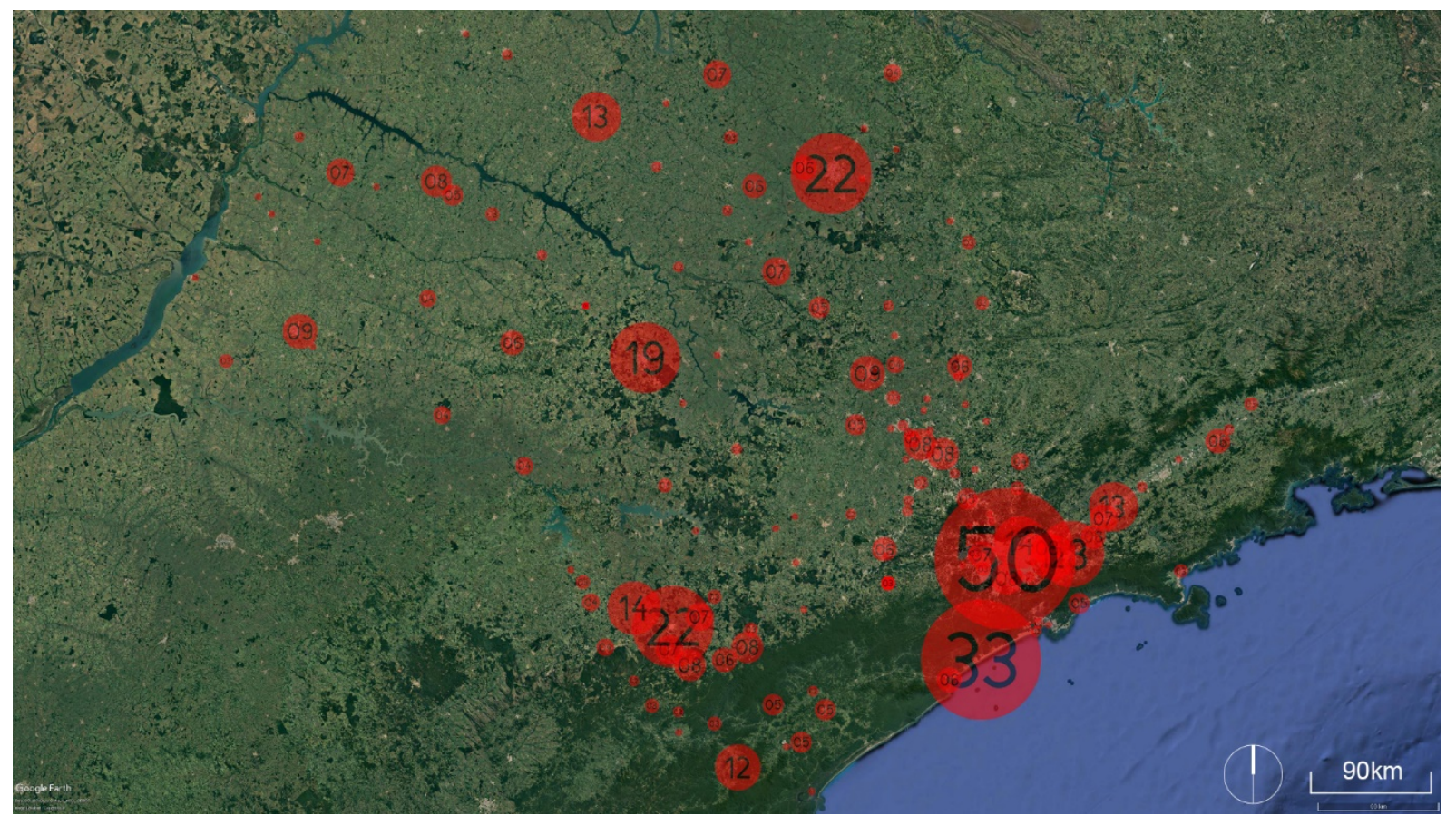

Figura 07: Empreendimentos contratados pelo programa Minha Casa Minha Vida no estado de São Paulo.

(Fonte: Google Earth, à partir dos dados disponibilizados pela Caixa Econômica Federal em abril de 2017.)

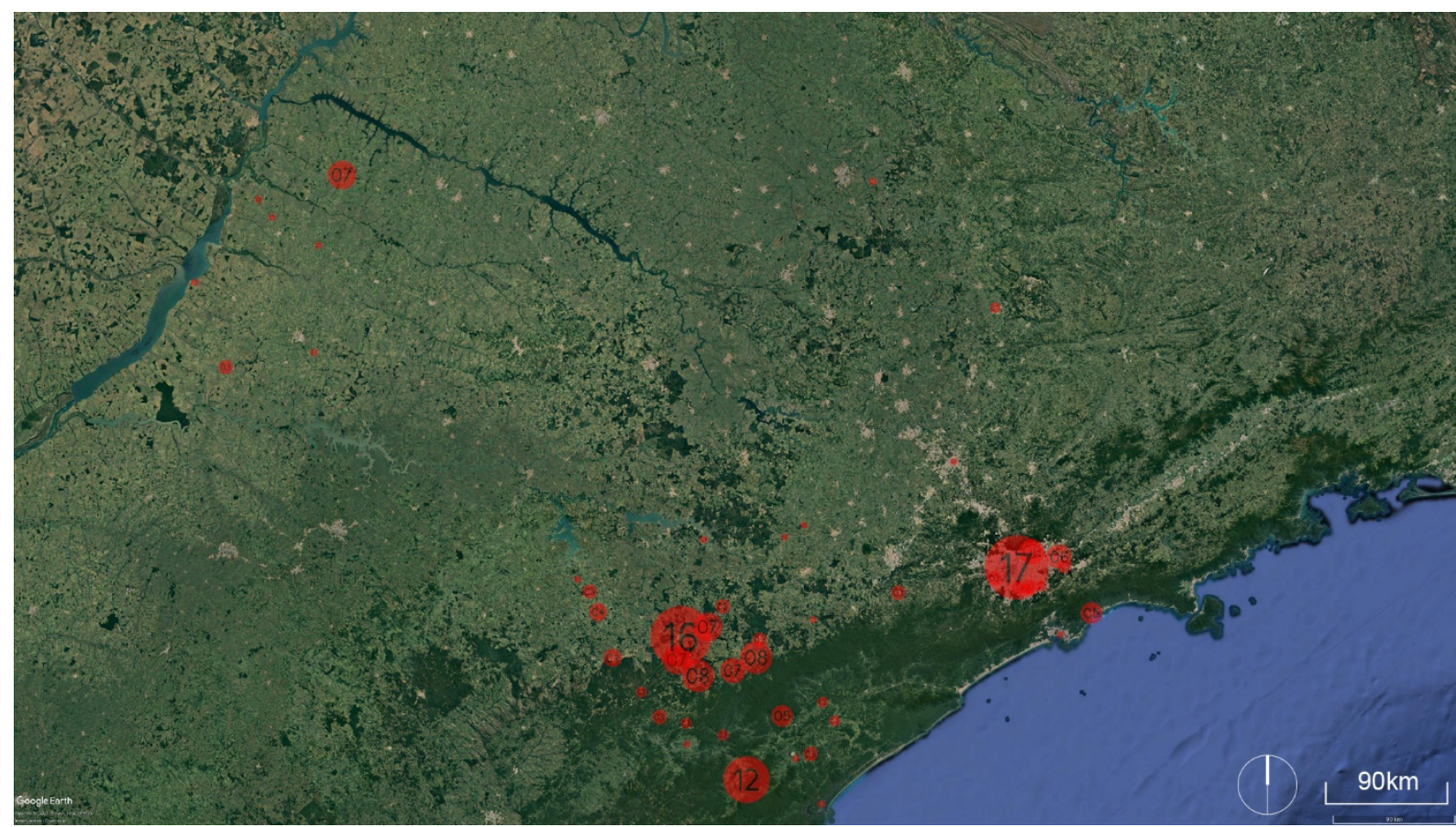

Figura 08: Empreendimentos contratados pelo programa Minha Casa Minha Vida do estado de São Paulo, cujos contratos apresentam alguma forma de participação popular.

(Fonte: Google Earth, à partir dos dados disponibilizados pela Caixa Econômica Federal em abril de 2017.)

Para análise dessa hipótese, foram levantados dois exemplos práticos: o primeiro na cidade de São Carlos, constituindo-se como um modelo de produção de habitação a partir do ponto de vista de um mercado imobiliário crescente e impositivo. O segundo, como contraexemplo e alternativa a esses processos de alienação, a reestruturação da favela do Sapé, localizada na zona oeste da cidade de São Paulo.

Os exemplos procuraram ser ilustrativos da lógica de micro-urbanismo como processo pedagógico e social, para além de ser apenas uma estratégia urbanística ou arquitetônica. Esse argumento prático vem a tencionar os modelos de políticas públicas urbanas, com foco em habitação, que, como verificado, tem se produzido no 
sentido de garantir quantidade de produção, acima de qualidade, além de ser vastamente usada como artifício de exclusão social e valorização de terras para especulação imobiliária.

\subsubsection{Estudo de caso preliminar: MCMV Abdelnur - São Carlos/SP e ocupação "Em busca de um sonho"}

A cidade de São Carlos possui uma população estimada de 243.765 habitantes segundo o censo do Instituto Brasileiro de Geografia e Estatística (IBGE) realizado em 2010, e possui vazios urbanos em profusão em sua região central. No entanto, foram implantados cinco empreendimentos MCMV, dos quais quatro são da mesma construtora, e somam 2.792 unidades habitacionais ${ }^{4}$.

O conjunto Minha Casa Minha Vida Abdelnur (Figura 09) foi recentemente construído e está em vias de consolidação. Ele é, contudo, um exemplo recorrente na realidade urbana brasileira da implantação deste tipo de política. Localizado longe da malha urbana e com pouca estrutura, ele se configura como uma densa bolha de habitação no meio rural.

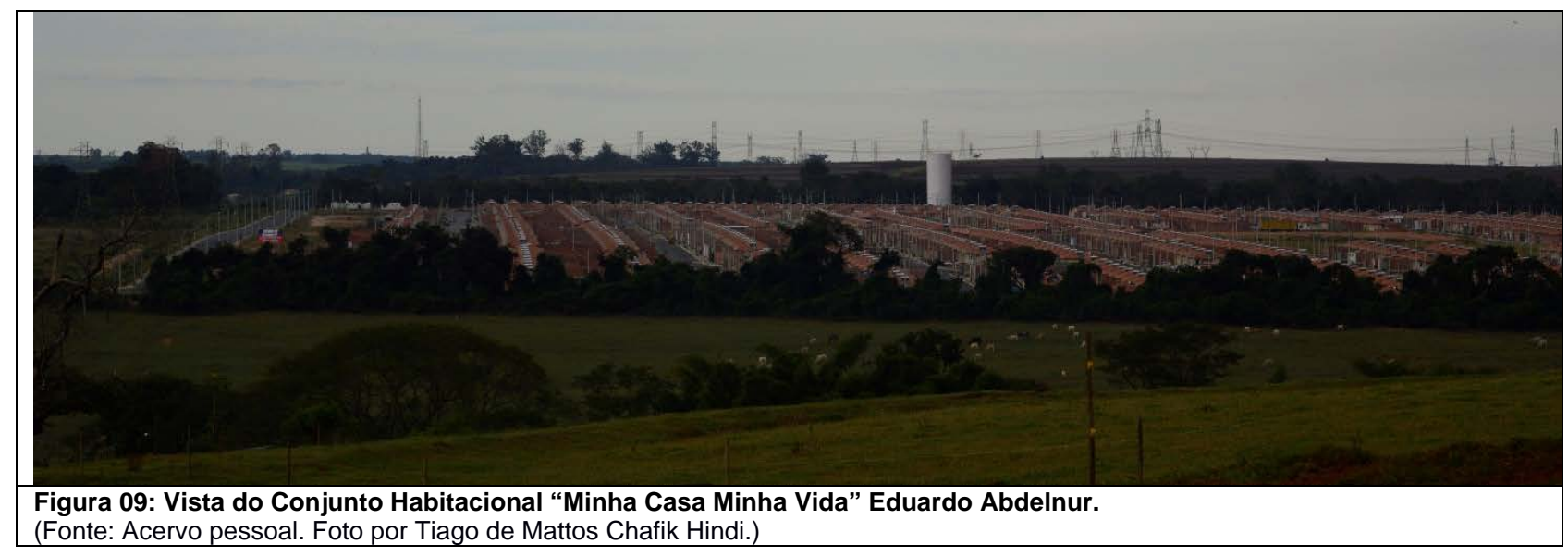

Compõe-se de 986 unidades habitacionais, ou seja, aproximadamente um terço de todas as unidades habitacionais construídas através deste programa na cidade de São Carlos. Durante visitas a região, realizadas em maio de 2017, percebe-se a desertificação causada por vários aspectos, dentre os quais a falta de qualificação dos espaços residuais e institucionais, a falta de equipamentos e a não diversificação de usos. Somada a isso, a falta de mobilidade e o distanciamento em relação ao centro impõe um movimento pendular em relação as zonas de concentração de trabalho formal, que dura em torno de uma hora.

Os espaços livres se mostram negligenciados, assim como os espaços de lazer. Isso se dá pela falta de identidade com o lugar por parte dos moradores que, dada a natureza impositiva do projeto, não se apropriam ou zelam pelo espaço conjunto.

Próximo ao conjunto MCMV se localiza uma ocupação realizada por um movimento social urbano que caracteriza o coletivo "Em busca de um sonho", que luta por moradia digna na cidade de São Carlos. Percebese um envolvimento político e social muito maior no caso da ocupação, em vista da intensa atividade política envolvida no processo. Como afirma Bibiana (2017):

[este coletivo] Vai conseguir suprir as necessidades ali daquele momento, e vai conseguir também, começar a criar consciência pela própria prática e entender o porquê que ela tem que fazer isso, sendo que não é uma função determinada pra ela, e ao invés de ser um ônus, se tornar um ônus e tirar do Estado essa função de exonerar ele, começa a ser uma ferramenta pra empoderar a sociedade a participar ativamente. (Bibiana, 2017)

Essa diferença reflete diretamente no uso do espaço público e/ou coletivo, no qual um se encontra em estado de abandono (MCMV) e no caso da ocupação, de trabalho cooperativo, apesar das dificuldades encontradas pela precariedade das moradias. Em contrapartida, percebe-se a consolidação de um grupo enquanto sujeitos políticos, retomando o papel coletivo da cidade.

\footnotetext{
${ }^{4}$ Dados obtidos a partir de informações coletadas junto a Caixa Econômica Federal em abril de 2017;
} 


\subsubsection{Estudo de caso preliminar: Conjunto Sapé - São Paulo/SP}

Em paralelo às políticas públicas de habitação, contudo, existem projetos alternativos às formas de produção da cidade. O exemplo abordado é um conjunto habitacional voltado a urbanizar o assentamento precário da favela do Sapé, na zona oeste da cidade de São Paulo.

Este projeto (Figura 10), visitado no dia 13 de maio de 2017, foi escolhido pelo seu caráter de êxito quanto a sua proposta inicial, de integração urbana de uma região isolada da malha urbana, e socialmente, de formação de uma identidade coletiva e organizada. Desde sua concepção, o projeto foi voltado a inclusão da população que o habitaria, e foi posto em prática após anos de convívio e debate com a população local. Trabalho este, levado a cabo pela associação de profissionais de arquitetura a assistentes sociais, num processo de contínua organização social.

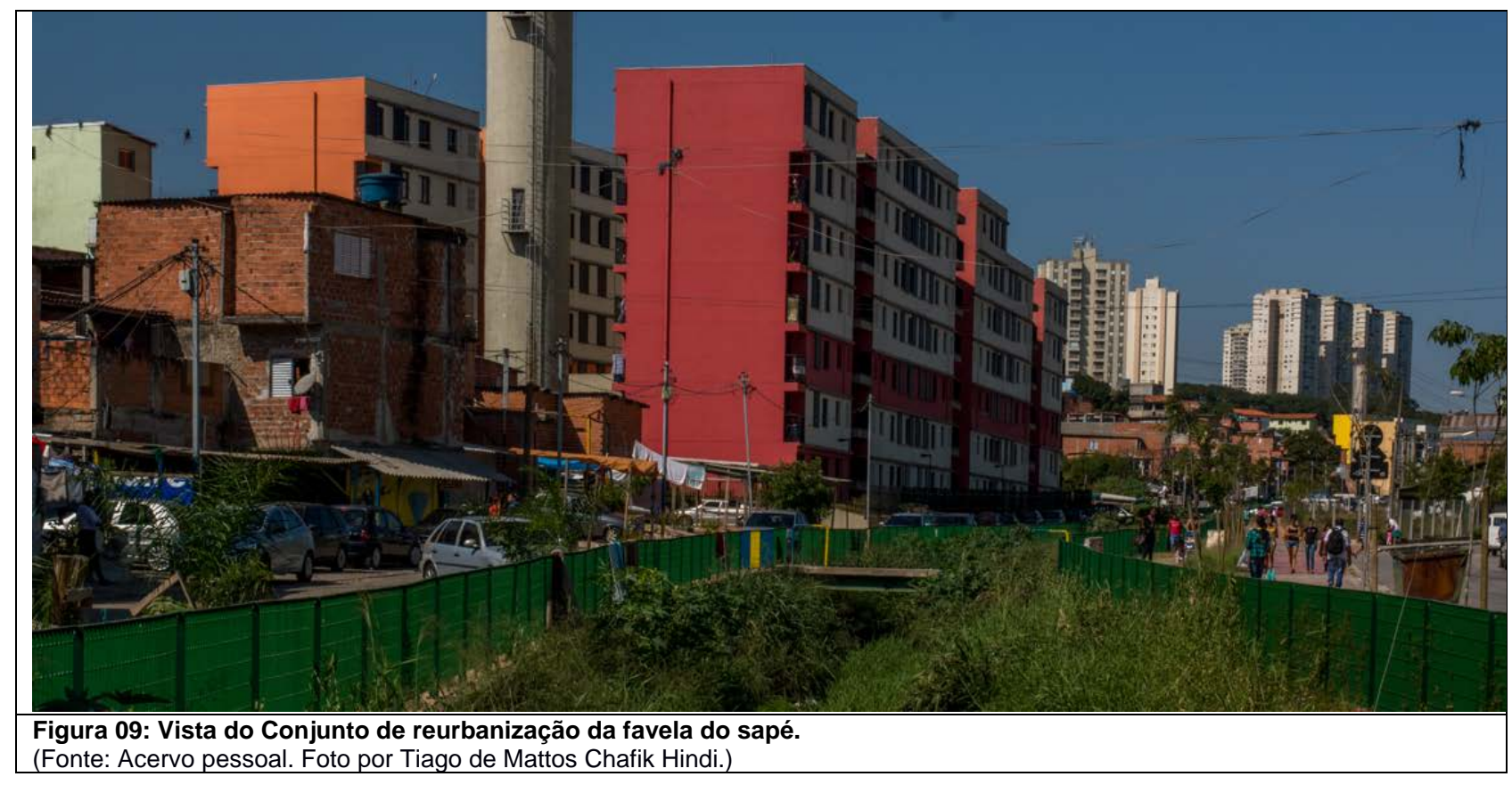

Durante a concepção e desenvolvimento deste projeto, as diretrizes e demandas das entidades envolvidas foram traduzidas ao desenho e a conformação do objeto arquitetônico resultante. Dessa forma, nenhuma ação projetual foi instituída, mas sim organizada pelo escritório de arquitetura em função do coletivo. As vivências do escritório com os futuros moradores também contribuíram para a identificação de comportamentos peculiares da vizinhança, do uso do espaço característico, como por exemplo o escalonamento do tamanho e do caráter de privacidade das áreas livres.

Essas práticas, contudo, esbarram em questões de políticas públicas, nas quais estão inseridas. Este projeto, especificamente, teve crises junto às construtoras responsáveis por sua construção por motivos orçamentários, quanto a elementos de projeto decididos e escolhidos por moradores, como as largas circulações (bastante utilizadas pelos moradores como espaço de convívio), e as varandas.

O programa de implementação do projeto também não previa a instalação de usos mistos, de forma que os pequenos comércios que existiam foram forçados a se deslocar ou desaparecer, forçando seus donos a buscar empregos longe de suas moradias. A morosidade do poder público também interfere na obra construída, pois menos da metade das pessoas que foram removidas já puderam reclamar a vaga no conjunto, mas as áreas livres estão novamente em processo de ocupação irregular por demanda de moradia.

Contudo, apesar do contexto social conturbado, a articulação social promovida pela assistência técnica e pela propria população servida consolidou o conjunto de maneira pronfuda. A força política que os moradores deste conjunto possuem é capaz de promover transformações no seu contexto imediato, e até de enfrentamentos com o poder público para garantia de prosseguimento do projeto. 


\section{Análise e discussão}

Até o momento, a pesquisa se pautou na busca de dados capazes de caracterizar a situação presente, com o levantamento das políticas públicas referentes à habitação dos respectivos casos de análise (Montreal e São Paulo) e a elaboração de uma cartografia ilustrativa destas práticas, que nos permite entender como se configuram as práticas espacialmente, através do cruzamento de dados.

A metodologia empregada, tripartida entre estudo teórico, entrevistas e análise empírica mostrou-se extremamente eficaz na produção de informações conclusivas quanto a tese elaborada incialmente. A partir de um questionamento e estudo teórico, as entrevistas permitiram novos olhares ao tema de pesquisa, que contribuíram para uma leitura empírica mais apurada.

Em vista destas informações levantadas durante o processo de pesquisa, é possível vislumbrar como a situação presente se configura. Como nos mostram os mapas 01 a 04 da cidade de Montreal, existe uma forte relação entre os programas de fomento de cooperativas de habitação e a renda e a densidade demográfica, o que ocorre no estado de São Paulo também.

A situação brasileira, porém, é fruto de uma urbanização recente, intensa e consequentemente desorganizada. Nesse sentido, a busca pela quantidade imediata atropela questões de qualidade arquitetônica e urbana, conforme afirma Menezes:

[...] São notórias as dificuldades associadas à implementação de um eficaz sistema de planeamento urbano, nomeadamente quando de um crescimento descontrolado, rápido e desordenado do território e ao qual se relacionam um conjunto de fragilidades: falta de infraestruturas, marginalidade sócio urbanística, desigualdades na ocupação do espaço, (etc.) (Menezes, 2015)

Os programas habitacionais das políticas públicas de ambos os casos estão inscritos em dinâmicas urbanas ditadas por uma forte especulação, causada em grande parte pelo capital imobiliário financerizado, que impele coletividades a possível exclusão.

A realidade canadense também ilustra este cenário de crises, apesar do forte histórico de fomento a essas inciativas pelo Estado. Na cidade de Montreal se sebressai uma ampla manifestação desta forma cooperativa de habitar a cidade, como nos mostram os mapeamentos. A verificação empírica nos mostra, contudo, que esses processos estão hoje em declínio.

Percebe-se que a valorização das áreas do centro sul da cidade de Montreal, por exemplo, está sendo influenciada por uma recente reconfiguração do mercado imobiliário que reforça questões de exclusão social. As reconversões dos comércios das áreas afetadas e a produção de habitações de alto custo elevam o preço de manutenção das cooperativas existentes. Estas são, portanto, forçadas a fecharem, por serem em geral, voltadas a um público de menor poder aquisitivo e densamente povoadas, como nos mostra o levantamento cartográfico. Essa configuração presente nos leva a questionar como se organizará o espaço através do tempo, e como será a metamorfose dessa cartografia nos próximos anos.

Essas questões, associadas à crescente e recorrente gentrificação dos centros urbanos, coloca os empreendimentos habitacionais para populações de grande vulnerabilidade em lugares afastados e de pouca mobilidade urbana, conforme se verifica no conjunto Minha Casa Minha Vida Abdelnur. Segundo Métra (2012), é preciso uma coligação entre poder público e a iniciativa popular, sendo, portanto, necessário repensar formas de interação entre entes políticos e o corpo social.

Dessa forma pôde-se concluir a dimensão política dessa prática projetual, reforçada pelas entrevistas realizadas, evidenciando os conflitos protagonizados pelos agentes urbanos que constituem lutas e disputas pela cidade, tanto para o caso de Montreal, quando para o do estado de São Paulo. Especificamente em contextos em que processos cooperativos e participativos se mostraram presentes e articuladores, mas que atualmente vem se mostrado decadentes, pelas próprias iniciativas populares quando esquecidos pelas políticas públicas, num cenário de pouquíssimo investimento e fomento das mesmas.

Evidenciam-se, portanto, processos de apropriação do capital no âmbito político, marcando as políticas públicas como mecanismos do capital financeiro, especulando sobre a cidade (Rolnik, 2015). Este cenário 
nos mostra, portanto, os reflexos da produção contemporânea nas cidades e a desigualdade como seus agentes participas atuam. Dessa forma, é necessário questionar como se dará a metamorfose dos núcleos urbanos, e como será seu desenvolvimento social e político refletido e materializado no espaço urbano. É visível a retração do poder popular depois de uma década de empoderamento. Os recentes acontecimentos políticos no mundo, e no Brasil especificamente, marcam um pondo de retomada de individualismos, como discute Comaru:

[As] agendas (...) mais progressistas, e de alguma forma mais à esquerda, estão em um momento de refluxo, e a gente tem assistido um avanço importante das agendas conservadoras, agendas da direita, que de alguma forma privilegiam o capital, mais o capital em detrimento do trabalho, do trabalhador, da organização do trabalhador. (...) Políticos e gestores que prometem resultados importantes em curtíssimo prazo, e soluções simples e fáceis, enfim, soluções que você pode individualmente ter uma sensação de melhora, mas pra sociedade como um todo tem um prejuízo. (Comaru, 2018)

Se faz importante, portanto, aprofundar o entendimento sobre as dinâmicas de consolidação dos projetos cooperativos junto a agentes inseridos nestes processos participativos (como coordenadores das cooperativas de habitação, representantes do poder público que estejam associados às questões habitacionais, membros da academia e membros de coletividades que tenham participado ou participem de processos de consolidação de cooperativas de habitação). Dessa forma, podem ser apontadas estratégias urbanas mais coerentes com o cotidiano social, e apropriação benfazeja do espaço urbano, seja público ou privado.

Em todas as entrevistas realizadas, principalmente a realizada com Eleusina de Freitas, foi frisada a importância da participação popular para o sucesso de um projeto urbano e o apoio fundamental do poder público. Em função da participação e da aplicação política dos usuários, é notória a identidade e manutenção do objeto projetado, em todos os cenários observados e descritos, seja no Canadá quanto no Brasil. Para o bom desenvolvimento político do Estado, é fundamental que este dê abertura e confiança para o poder popular de decisão, acima de simples consulta, assim como afirma Eleusina (2018): "que ele [o processo participativo] precisa e ao mesmo tempo ele se separa da política, porque a política não tem força pra segurar o processo que a sociedade tem". A arquiteta explica que, em todas as experiências nas quais teve contato, em especial em Vinhedo e Jundiaí, o processo adquiriu grande poder de transformação e capacitação popular e conseguiu ser aprovado com apoio do poder público e do poder judiciário.

Também foi reforçada a necessidade de participação dos usuários no processo de projeto pelo histórico de consolidação das políticas de cooperativismo. Como nos mostra o histórico de elaboração dessas políticas, a concentração de poder de definição nos diversos níveis do corpo Estatal leva a um excesso de burocracia que tende a morosidade de ação das políticas públicas. A experiência canadense nos mostra como pode ser eficaz a implementação dessas iniciativas, concedendo a coletivos a possibilidade de gestão de seu projeto habitacional.

Apesar disso, como nos mostram os dados levantados, disponibilizados pelos agentes envolvidos nestas políticas públicas, vê-se cada vez mais o corpo social minguando e dando lugar para agentes financeiros e capitalizados. Evidencia-se, portanto, a importância da continuidade deste mapeamento e acompanhamento, para que essas iniciativas permaneçam em atividade, e produzam espaços urbanos com maior vitalidade e qualidade social.

É mister, como desdobramento desta pesquisa, buscar o aprofundamento nas dinâmicas de consolidação dos projetos cooperativos, com agentes inseridos nestas estratégias participativas, como coordenadores das cooperativas de programas específicos, seja em Montreal, quanto no estado de São Paulo, que estejam associados às questões habitacionais, membros da academia, que possuam conhecimento sobre o assunto e membros de coletividades que tenham participado ou participem de processos de consolidação de cooperativas de habitação. Com a análise destas potencialidades e entendendo estas dinâmicas como processos políticos, é possível que possam ser formuladas alternativas práticas à situação presente e reestruturação da condição social.

05. Referências bibliográficas 
ALENCAR, Anna Karina (2010), A inserção dos movimentos sociais na questão urbana: a produção social do habitat, Natal, Seminário nacional de governança urbana e desenvolvimento metropolitano.

ARNSTEIN, Sherry R. (1969), A Ladder of citizen participation, JAIP, no 4, julho 1969, pp. 216-224.

BAUMAN, Zygmunt (2009), Confiança e Medo na Cidade, Rio de Janeiro, Zahar.

BLANC, Maurice. (1998), Participation des habitants et politique de la ville. La démocratie locale. représentation, participation et espace public, actes du colloque d'Amiens, pp. 177-196.

BONDUKI, N (2014). Pioneiros da habitação social: cem anos de política pública no Brasil. São Paulo: Editora UNESP: Edições SESC, 2014. v.1.

BOUCHARD, Marie; HUDON, Marcellin (2005), Le logement coopératif et associatif comme innovation sociale émanant de la societé civile, Revue Interventions économiques, $\mathrm{n}^{\circ} 32$, ano 2005 , disponível no site $<$ http://interventionseconomiques.revues.org/856>.

BUZZAR, Miguel; TEIXEIRA, Catharina; RAFFAELLI, Cristina R.; et al. (2014), Minha Casa Minha Vida Entidades e as possibilidades de renovação da política habitacional, Maceió, ENTAC.

COMARU, Francisco de Assis. Entrevista semi-estruturada: Processos participativos e cooperativismo no Brasil. Instituto de Arquitetura e Urbanismo da Universidade de São Paulo (USP), São Carlos, SP-Brasil, 2018.

DECROLY, Jean-Michel (2003), Revisiting the diversity of gentrification: neighbourhood renewal processes in Brussels and Montreal, Urban Studies, Volume 40, nº 12, novembro 2003.

FERREIRA, Regina (2012), Movimentos de moradia, autogestão e política habitacional no Brasil: do acesso à moradia ao direito à cidade, Buenos Aires, $2^{\circ}$ Forum de Sociologia "Justiça social e democratização", 01 a 04 de agosto de 2012.

De FREITAS, Eleusina Lavôr Holanda. Entrevista semi-estruturada: Processos participativos e cooperativismo no Brasil. Instituto de Arquitetura e Urbanismo da Universidade de São Paulo (USP), São Carlos, SP-Brasil, 2018.

ONU-Habitat (2016), Nova Agenda Urbana, Quito, Conferência Habitat 3.

HARVEY, David. (2013), Condição Pós-Moderna, São Paulo, Loyola.

MENEZES, Marluci. (2015), Compreender os micro-processos sociais de criação de espacialidades cinéticas no (re) pensar das práticas de urbanismo, Revista Belas Artes, 15 edição, junho de 2015.

MÉTRA, Brigitte. (2012) Pour un autre mode de "ville". Vers un micro-urbanisme: les enseignements de l'expérience mexicaine de programme d'amélioration de quartier a México. Le laboiratoire politique, junho 2012.

NAIME, Jéssica. (2010). A política de habitação social no governo Lula: dinâmicas e perspectivas. Natal, Seminário nacional de governança urbana e desenvolvimento metropolitano.

PARAZELLI, Michel; LATENDRESSE, Anne (2006). Penser les conditions de la démocratie participative, Revue Nouvelles Pratiques Sociales. Volume 18, n² 2, primavera 2006, p.15-23;

PESCADOR, Flora (2011). Del macro al micro-urbanismo, Urbact III, documento html disponível em: $<$ http://ecosistemaurbano.org/urbanismo/urbact-del-macro-al-micro-urbanismo/>. [Atualização: 4 de abril de 2011 (consulta: 21 junho 2016)].

RIZEK, Cibele; AMORE, Caio; CAMARGO, Camila; et al. (2014). A insersão urbana através da produção do MCMV-Entidades no estado de São Paulo: abordagem etnográfica de casos selecionados, São Paulo, ENANPARQ. 
ROLNIK, Raquel. (2015). Guerra dos Lugares: a colonização da terra e da moradia na era das finanças. São Paulo: Boitempo.

SILVEIRA, Bibiana Barreto. Entrevista semi-estruturada: Processos participativos e cooperativismo no Brasil. Instituto de Arquitetura e Urbanismo da Universidade de São Paulo (USP), São Carlos, SP-Brasil, 2017.

ZETLAOUI-LÉGER, Jodelle. (2005) L'implication des habitants dans des micro-projets urbains: enjeux politiques et propositions pratiques, Bruxelas, Les cahiers de l'école d'architecture de La Cambre.

ŽIŽEK, Slavoj (2012). O retorno da má Coisa étnica. In: Slavoj Zizek (org). O ano em que sonhamos perigosamente, São Paulo, Boitempo. Págs 41-52. 